\title{
ANALISIS INTERAKSI OBAT PADA PASIEN HIPERTENSI GERIATRI YANG MENJALANI RAWAT JALAN DI RS PKU MUHAMMADIYAH YOGYAKARTA AGUSTUS 2009-AGUSTUS 2010
}

\author{
Dhanang Prawira Nugraha(05613120) ${ }^{1^{*}}$, Saepudin, Joko Sudibyo \\ Program Studi Farmasi Universitas Islam Indonesia
}

\begin{abstract}
Increasing age can cause a variety of degenerative disease, one of which is hypertension. One issue is the treatment of geriatric polypharmacy the drug interactions may pose clinical problems that require a careful monitoring and action, for example the use of antihypertensives. This study aims to determine the picture of drug use and the relationship between the number of medication and comorbidities with potential drug interactions. This study is an observational analytic study using cross sectional study design. Data is retrospectively collected by using affordable population that meet the criteria. The determination of the relationship between the amount of active drug substance and the number of comorbidities, with the potential for drug interactions are analyzed using a linear regression. The results show that the most widely prescribed antihypertension research is in the singular (35.47\%) of amlodipine (46.37\%), about $51.27 \%$ of the recipes contain a potential for drug interaction, with the potential drug interactions at the level of the most significant (45.78\%). The results of linear regression analysis showing the relationship between the amount of active drug substances and the number of potential drug interactions can be denoted by the equation $y=0.386 x-0.385$, but the relationship is very weak because of the pearson correlation ( $r$ ) 0.491 . The relationship between the number of comorbiditie and potential drug interactions can be denoted by the equation $y=0.416 x+$ 0.806 , but the relationship is very weak because of the pearson correlation (r) 0.06 .
\end{abstract}

Key words: drug interaction, hypertension, geriatric, outpatient, PKU Muhammadiyah 
1. PENDAHULUAN

Penduduk usia lanjut atau geriatri mewakili sekitar $14 \%$ dari jumlah penduduk dunia. Jumlah orang usia lanjut di Amerika sekitar $12,4 \%$ dan diperkirakan pada tahun 2030 meningkat menjadi $20 \%$, dengan $2,5 \%$-nya adalah orang-orang déngan usia 85 tahun atau bahkan lebih. Jumlah penduduk usia lanjut atau geriatri di Indonesia mencapai sekitar 13 juta pada tahun 2005 (Lindblad;2005;Anonim, 2010).

Definisi geriatric di Indonesia menurut undang-undang no.13/1998 tentang kesejahteraan usia lanjut adalah seseorang yang telah mencapai usia 60 tahun(Soejono, 2004).

Proses bertambahnya usia dapat menyebabkan penurunan fungsi organ tubuh yang dapat menyebabkan berbagai penyakit degeneratif, salah satunya adalah hipertensi. Nilai tekanan darah meningkat seiring bertambahnya usia, dan hipertensi adalah penyakit yang umum dialami oleh orang tua. Kebanyakan pasien memiliki tekanan darah prehipertensi didiagnosa pada usia 30-40 tahun. Prevalensi hipertensi pada tahun 2000 pada usi lanjut $\geq 60$ tahun lebih tinggi dibandingkan usia yang sama pada tahun 1988(Saseen, 2005).

Hasil penelitian yang dilakukan oleh Wolf-Maier pada tahun 2003 menunjukkanbahwa dinegara Amerika dan Kanada penderita hipertensi berturutturut $27,8 \%$ dan $27,4 \%$ sedangkan pada enam Negara di Eropa antara lain, Itali, Swedia, Inggris, Spanyol, Finlandia dan Jerman rata-rata penderita hipertensi di negara-negara tersebut sebesar $44,2 \%$ (Wolf-Maier, 2003).

Salah satu faktor resiko yang menjasi permasalahan dalam pengobatan pada psien geriatri adalah pengguanaan banyak obat secara bersama-sama atau disebut polifarmasi. Salah satu definisi yang digunakan untuk mendefinisikan polifarmasi adalah penggunaan 5 atau lebih obat secara bersamaan (Midlov, 2009).

Di Amerika 4,6\% pasien masuk runah sakit dikerenakan adanya interaksi obat-obat. Dua studi lainnya di Amerika dan di Swedia menunjukkan bahwa $25-27 \%$ pasien memiliki kombinasi obat yang potensial membawa perubahan sedang sampai besar pada outcome terapinya (Bjorkman, 2007). Faktor-faktor yang berhubungan dengan interaksi obat antara lain adalah menggunakan 5 macam obat secara bersamaan, usia lebih dari 60 tahun, dan memiliki penyakit kardiovaskular(Dubova, 2007).

Penelitian tentang potensi interaksi obat pada pasien geriatric belum pernah dilakukan sehingga peneliti merasa perlu mengangkat masalah ini untuk melihat bagaimana pengruh antara jumlah obat dab penyakit penyerta terhadap potensi terjadinya interaksi obat pada pasien hipertensi geriatri di RS PKU Muhammadiyah Yogyakarta. 
.Dhanang, Saepudin, Joko

\section{METODE PENELITIAN}

Penelitian ini merupakan penelitian observasional analitik dengan menggunakan rancangari penelitian cross sectional (potong lintang). Pengambilan datanya dilakukan secara retrospektif, dengan menelusuri data pasien pada rekam medik pengobatan pasien hipertensi yang menjalani rawat jalan selama bulan Agustus 2009 - Agustus 2010. Subyek penelitian ini adalah rekam medik pasien yang memenuhi kriteria inklusi yaitu pasien mendapatkan terapi macam obat, Pasien hipertensi dengan penyakit penyerta dan tanpa penyakit penyerta, Pasien geriatri adalah pasien dengan usia tahun, serta criteria eksklusi, rekam medik tidak dapat terbaca.

Data analisis dengan menggunakan metode deskriptif dan disajikan dalam bentuk tabel dan grafik serta dihitung presentasenya, sedangkan potensi interaksinya dinilai dengan menggunakan Interaksi checker (Anonim, 2010), drug interaction fact (Tatro, 2001), drug interaction (Stockley, 2005).

\section{HASIL DAN PEMBAHASAN}

Hasil pengolahan data ditetapkan pasien yang dimasukkan dalam penelitian ini sejumlah 100 pasien dengan total lembar resep sebanyak 358 yang memenuhi kriteria inklusi dan eksklusi yang telah ditetapkan.
Tabel 1 Presentase Pasien Hipertensi

\begin{tabular}{|c|c|c|c|}
\hline $\begin{array}{l}\text { Karakteri } \\
\text { stik }\end{array}$ & Kategori & \begin{tabular}{|l|} 
Juml \\
ah
\end{tabular} & $\begin{array}{l}\text { Present } \\
\text { ase }\end{array}$ \\
\hline \multirow{2}{*}{$\begin{array}{l}\text { Jenis } \\
\text { Kelamin }\end{array}$} & Laki-laki & 41 & $41 \%$ \\
\hline & \begin{tabular}{|l} 
Perempua \\
n \\
\end{tabular} & 59 & $59 \%$ \\
\hline \multirow[t]{3}{*}{ Usia } & $60-69$ & 51 & $51 \%$ \\
\hline & $70-79$ & 36 & $36 \%$ \\
\hline & $80-89$ & 13 & $13 \%$ \\
\hline \multirow{10}{*}{$\begin{array}{l}\text { Jumlah } \\
\text { zat aktif }\end{array}$} & 2 & 51 & $14.25 \%$ \\
\hline & 3 & 89 & $24.86 \%$ \\
\hline & 4 & 93 & $25.98 \%$ \\
\hline & 5 & 45. & $12.57 \%$ \\
\hline & 6 & 35 & $9.78 \%$ \\
\hline & 7 & 22 & $6.15 \%$ \\
\hline & 8 & 11 & $3.07 \%$ \\
\hline & 9 & 9 & $2.51 \%$ \\
\hline & 10 & 2 & $0.56 \%$ \\
\hline & 11 & 1 & $0.28 \%$ \\
\hline \multirow{5}{*}{$\begin{array}{l}\text { Jumlah } \\
\text { Antihipert } \\
\text { ensi }\end{array}$} & Tunggal & 127 & 35.47 \\
\hline & $\begin{array}{l}2 \\
\text { kombinas } \\
\text { i obat }\end{array}$ & 122 & 34.08 \\
\hline & $\begin{array}{l}3 \\
\text { kombinas } \\
\text { i obat }\end{array}$ & 68 & 18.99 \\
\hline & $\begin{array}{l}4 \\
\text { kombinas } \\
\text { i obat } \\
\end{array}$ & 5 & 1.40 \\
\hline & $\begin{array}{l}\text { Tidak } \\
\text { mengand } \\
\text { ung } \\
\text { antihipert } \\
\text { ensi }\end{array}$ & 36 & 10.06 \\
\hline
\end{tabular}

Dari Tabel 1 dapat diketahui bahwa pasien hipertensi pada geriatri lebih banyak diderita oleh perempuan (59\%), hal ini dikarenakan pada perempuan usia lanjut hormon estrogen dan progesterone telah berkurang, sehingga terjadi kekakuan pada pembuluh darah dan profil lipid yang apda akhirnya akan meningkatkan tekanan darah.

Hasil pengelompokan pasien berdasarkan usia diperoleh jumlah 
pasien terbanyak adalah kelompok usia 60-69 tahun (51\%). Yang kemungkinan terkait dengan rata-rata usia harapan hidup penduduk Yogyakarta yang berkisar antara 60-70 tahun yang artinya bahwa populasi penduduk dengan usia diatas 70 tahun memang jumlahnya sedikit. Di daerah dengan usia harapan hiduplebih tinggiatau lebih rendah kemungkinan kana diperoleh gambaran yang berbeda terkait distribusi pasien hipertensi geriatri berdasarkan kelompok usia.

Berdasarkan kelompok jumlah zat aktif dalam lembar resep, kelompok lembar resep paling banyak adalah yang berisi 4 zat aktif $(25,98 \%)$, dengan jumlah rata-rata zat aktif adalah 6,5 zat aktif. Hasil ini realtif lebih rendah dibandingkan dengan penelitian di negara Eropa yang rata-rata pasien usia lanjut menerima 7 kombinasi obat (Bjorkman, 2002).

Selain untuk mengobati penyakit secara utama yang dialami pasien, zat aktif obat yang diresepkan biasanya juga ditujukan untuk mengobati penyakit-penyakit penyerta atau komplikasi dari penyakit utama. Suplemen-suplemen untuk tindakan suportif juga banyak diresepkan untuk pasien geriatri dalam penelitian ini, kemungkinan ditujukan untuk meningkatkan daya tahan tubuh dan kondisi kesehatan pasien secara umum.

Dari jumlah lembar resepyang memenuhi kriteria pada penelitian ini terdapat sebanyak 131 lembar resep
(36,59\%) yang mengandung antihipertensi tunggal dan hal ini sama dengan penelitian yang dilakukan Ariawan (2010) tentang peresepan antihipertensi di apotek wilayah kabupaten Sleman yang lebih banyak dalam bentuk tunggal, walaupun dengan presentase yang jauh berbeda $(81,76 \%)$ (Ariawan,2010).

Pasien dengan tekanan darah yang tidak terkontrol dengan antihipertensi tunggal umumnya akan mendapatkan kombinasi antihipertensi, dan dalam penelitian ini terdaat 122 lembar resep $(34,08 \%)$ dengan kombinasi 2 antihipertensi.

Secara umum antihipertensi yang diresepkan pada pasien hipertensi geriatri yang menjalani rawat jalan pada umumnya berupa antihipertensi tunggal $(35,47 \%)$, penggunaan antihipertensi secara tunggal dapat meminimalkan kejadiań interaksi obat dan dapat mengurangi adverse drug reaction karena penggunaan bersama obat antihipertensi lainyya. Sebanyak 166 lemba resep $(46,37 \%)$ terdapat amlodipin baik terdapat dalam kombinasi maupun tunggal hal ini berbeda dengan penelitian Ariawan (2010) tentang peresepan antihipertensi di apotek wilayah kabupaten Sleman yang menunjukkan bahwa captorpil adalah antihipetensi yang paling banyak digunakan si apotek wilayah Sleman. Pada penelitian ini antihipertensi yang paling banyak digunakan adalah amlodipin dimana penggunaan amlodipin (dihydropyridin 
calcium channel blocker) dan diuretik thiazide dapat menurunkan morbiditas dan mortilitas pada psien lanjut usia dengan hipertensi terisolasi (Saseen, 2005;Ariawan,2010).

Penggunaan captopril menempati posisi kedua sebanyak 103 lembar resep $(28,77 \%)$ terdapat captopril baik digunakan secara tunggal maupun dgunakan secara kombinasi. Captopril banyak diresepkan oleh dokter karena adanya penyakit penyerta seperti diabetes mellitus, gagal jantung maupun pasien dengan riwayat stroke. Captopril merupakan obat antihipertensi pilihan pertama untuk pasien-pasien dengan komplikasi atau penyakit penyerta tersebut (Saseen,2005).

Berdasarkan potensi interaksi obat yang dapat terjadi sebanyak 122 lembar resep $(34,08 \%)$ yang tidak memiliki potensi interaksi obat dan sisanya sebanyak 236 resep (65.92\%) memiliki potensi interaksi obat. Obat antihipertensi merupakan salah satu obat yang memerlukan pengaturan control dosis yang ketat supaya dapat mengontrol tekanan darah sehinga akan mengurangi komplikasi dari hipertensi tersebut salah satunya adalah stroke.

Dari 236 lembar resep yang memilliki interaksi obat terdapat beragam potensi interaksi obat yang kemungkinan terjadi interaksi. Terdapat maksimal 11 potensi interaksi obat dalam 1 resep atau sebesar $0,42 \%$ dan minimal 1 interaksi dalam 1 resep dengan presentase sebesar $51,27 \%$. Pada penelitian ini terdapat sebanyak $5.1,27 \%$ lembar resep yang memiliki 1 interaksi. Hal ini lebih tinggi daripada penelitian yang pernah dilakukan oleh Bjorkman di 7 negara eropa yang terdapat $46 \%$ yang memiliki 1 interaksi obat(Borkman, 2002).

Hasil analisis dari 236 lembar resep yang berpotensi mengalami interaksi obat terdapat berbagai macam interaksi berdasarkan level signifikansi mulai dari level 5 yang dapat mengancam nyawa hinga level signifikansi 2 yang memerlukan perhatian pada penggunaan kombinasi tersebut, dan hasilnya terdapat 450 macam interaksi obat yang jika dibagi berdasarkan tingkat signifikansinya terdapat 25 interaksi level $5(5,56 \%)$ dan interaksi yang terbanyak terdapat pada level signifikansi 4 yakni sebanyak 206 interaksi obat $(45,78 \%)$.

Tabel 2. Potenși Interaksi Obat

\begin{tabular}{|c|c|c|c|}
\hline \multicolumn{4}{|c|}{$\begin{array}{l}\text { Level Interaksi } \\
\text { Jumah } \quad \text { Prese }\end{array}$} \\
\hline \multirow{5}{*}{$\begin{array}{l}\text { Level } \\
5\end{array}$} & $\begin{array}{l}\text { Captopril - } \\
\text { Allopurinol }\end{array}$ & $\begin{array}{l}1 \\
0\end{array}$ & \begin{tabular}{|l|}
2,22 \\
$\%$ \\
\end{tabular} \\
\hline & $\begin{array}{l}\text { Irbesartan- } \\
\text { Spironolactone }\end{array}$ & 3 & \begin{tabular}{|l|}
0,67 \\
$\%$ \\
\end{tabular} \\
\hline & $\begin{array}{l}\text { Spironolactone- } \\
\text { Captopril }\end{array}$ & 3 & $\begin{array}{l}0,67 \\
\%\end{array}$ \\
\hline & $\begin{array}{l}\text { Valsartan - } \\
\text { Spironolactone }\end{array}$ & 3 & \begin{tabular}{|l|}
0,67 \\
$\%$
\end{tabular} \\
\hline & $\begin{array}{l}\text { Ramipril - } \\
\text { Allopurinol }\end{array}$ & 2 & $\begin{array}{l}0,44 \\
\%\end{array}$ \\
\hline \multirow[t]{2}{*}{$\begin{array}{l}\text { Level } \\
4\end{array}$} & $\begin{array}{l}\text { Asam Asetil } \\
\text { Salisilate - } \\
\text { Amlodipine }\end{array}$ & & $\begin{array}{l}4,67 \\
\%\end{array}$ \\
\hline & $\begin{array}{l}\text { Hydrochlorothiazie } \\
\text {-Allopurinol }\end{array}$ & $\begin{array}{l}1 \\
4\end{array}$ & $\begin{array}{l}3,11 \\
\%\end{array}$ \\
\hline
\end{tabular}




\begin{tabular}{|c|c|c|c|}
\hline & $\begin{array}{l}\text { Captopril - } \\
\text { Methampyrone }\end{array}$ & $\begin{array}{l}1 \\
1 \\
\end{array}$ & $\begin{array}{l}2,44 \\
\% \\
\end{array}$ \\
\hline & $\begin{array}{l}\text { Captopril- } \\
\text { Diclofenac }\end{array}$ & 7 & $\begin{array}{l}1,56 \\
\%\end{array}$ \\
\hline & $\begin{array}{l}\text { Theophylline - } \\
\text { Furosemide }\end{array}$ & 7 & $\begin{array}{l}1,56 \\
\%\end{array}$ \\
\hline \multirow{6}{*}{$\begin{array}{l}\text { Level } \\
3\end{array}$} & $\begin{array}{l}\text { Captopril - } \\
\text { Hydrochlorothiazid } \\
\text { e }\end{array}$ & $\begin{array}{l}1 \\
1\end{array}$ & $\begin{array}{l}2,44 \\
\%\end{array}$ \\
\hline & $\begin{array}{l}\text { Furosemide - } \\
\text { Captopril }\end{array}$ & $\begin{array}{l}1 \\
1\end{array}$ & $\begin{array}{l}2,44 \\
\%\end{array}$ \\
\hline & $\begin{array}{l}\text { Asam Asetil } \\
\text { Salisilate - } \\
\text { Bisoprolol }\end{array}$ & $\begin{array}{l}1 \\
0\end{array}$ & $\begin{array}{l}2,22 \\
\%\end{array}$ \\
\hline & $\begin{array}{l}\text { Glibenclamie - } \\
\text { Captopril }\end{array}$ & $\begin{array}{l}1 \\
0\end{array}$ & $\begin{array}{l}2,22 \\
\% \\
\end{array}$ \\
\hline & $\begin{array}{l}\text { Ramipril - } \\
\text { Furosemie }\end{array}$ & $\begin{array}{l}1 \\
0 \\
\end{array}$ & $\begin{array}{l}2,22 \\
\% \\
\end{array}$ \\
\hline & $\begin{array}{l}\text { Theophylline - } \\
\text { Diltiazem }\end{array}$ & $\begin{array}{l}1 \\
0 \\
\end{array}$ & $\begin{array}{l}2,22 \\
\% \\
\end{array}$ \\
\hline \multirow[t]{5}{*}{$\begin{array}{l}\text { Level } \\
5\end{array}$} & $\begin{array}{l}\text { Captopril - } \\
\text { Metformin }\end{array}$ & $\begin{array}{l}2 \\
6\end{array}$ & $\begin{array}{l}5,78 \\
\% \\
\end{array}$ \\
\hline & $\begin{array}{l}\text { Amlodipine - } \\
\text { Simvastatin }\end{array}$ & $\begin{array}{l}1 \\
7 \\
\end{array}$ & $\begin{array}{l}3,78 \\
\% \\
\end{array}$ \\
\hline & $\begin{array}{l}\text { Flunarizine - } \\
\text { Alprazolam }\end{array}$ & $\begin{array}{l}1 \\
3 \\
\end{array}$ & $\begin{array}{l}2,89 \\
\% \\
\end{array}$ \\
\hline & $\begin{array}{l}\text { Codein - } \\
\text { Phenyltoloxamine }\end{array}$ & 7 & $\begin{array}{l}1,56 \\
\% \\
\end{array}$ \\
\hline & $\begin{array}{l}\text { Codein- } \\
\text { Triprolidine }\end{array}$ & 3 & $\begin{array}{l}0,67 \\
\% \\
\end{array}$ \\
\hline
\end{tabular}

Pada tabel 2adalah potensi interaksi obat yang paling banyak muncul pada setiap level signifikansinya. Interaksi obat perlu mendapatkan perhatian dikarenakan dapat merubah efektifitas terapi maupun memberikan $A D R$ yang dapat memperparah keadaan pasien.

Dari hasil analisis didapatkan suatu hubungan yang dapat dinotasikan dengan persamaan $y=b x+a$ dengan hasil adalah $y=0,386 x-0,385$ untuk hubungan antara jumlah zat aktif dengan potensi kejadian interaksi obat dengan tingkat signifikansi sebesar 0,000 (lebih kecil dari 0,05) dapat dikatakan bahwa terdapat hubungan antara zat aktif dengan jumah potensi interaksi obat. Namun demikian, dari analisis juga menunjukkan bahwa hanya sebesar $24,1 \%$ potensi interasi obat yang dapat dijelaskan oleh jumlah zat aktif dan sebesar $75,9 \%$ potensi interaksi obat disebabkan oleh faktorfaktor lainnya (nilai R-square $=0,241$ ). Dengan nilai korelasi pearson ( $r$ ) sebesar 0.491 dapat nyatakan bahwa hubungan antara kejadian interaksi obat dengan jumlah zat aktif lemah (Tumbelaka, 1995).

Hubungan antara jumlah penyakit peryerta dengan jumlah kejadian interaksi obat dalam penelitian ini dianalisis secara statistik dengan menggunakan metode regresi linear dan didapatkan persamaan $y=0,416 x$ $+0,806$. Dengan tingkat signifikansi sebesar 0,000 (lebih kecil dari 0,05) dapat dikatakan bahwa terdapat hubungan antara jumlah penyakit penyerta dengan potensi interaksi obat. Namun demikian, dari hasil analisis dengan jumlah potensi interaksi obat sebesar $6,7 \%$ jumlah potensi interaksi obat yang dapat dijelaskan oleh jumlah penyakit penyerta dan sebesar $93,3 \%$ potensi interaksi obat dapat dijelaskan oleh faktor-fator lainnya (nilai R-square $=0,067$ ). Dengan nilai korelasi pearson (r) sebesar 0,06 maka hubungan antara kejadian interaksi obat dengan 
penyakit penyerta sangat lemah (Tumbelaka, 1995).

Tabel 3. Nilai Parameter Regresi Linier

\begin{tabular}{|l|l|l|}
\hline \multirow{2}{*}{ Parameter } & \multicolumn{2}{|c|}{ Nilai } \\
\cline { 2 - 3 } & $\begin{array}{l}\text { Hubungan } \\
\text { jumlah zat } \\
\text { aktif } \\
\text { dengan } \\
\text { potensi } \\
\text { interaksi } \\
\text { obat }\end{array}$ & $\begin{array}{l}\text { Hubungan } \\
\text { jumlah } \\
\text { penyakit } \\
\text { penyerta } \\
\text { dengan } \\
\text { potensi } \\
\text { interaksi } \\
\text { obat }\end{array}$ \\
\hline $\begin{array}{l}\text { Rata-rata } \\
\text { potensi } \\
\text { kejadian } \\
\text { interaksi } \\
\text { obat }\end{array}$ & 1.220 & 1.257 \\
\hline $\begin{array}{l}\text { SD potensi } \\
\text { kejadian } \\
\text { interaksi } \\
\text { obat }\end{array}$ & 1.395 & 1.393 \\
\hline $\begin{array}{l}\text { Korelasi } \\
\text { pearson }\end{array}$ & 0.491 & 0.259 \\
\hline R-square & 0.241 & 0.067 \\
\hline $\begin{array}{l}\text { Standar } \\
\text { error regresi }\end{array}$ & 1.220 & 1.347 \\
\hline Signifikansi & 0.000 & 0.000 \\
\hline
\end{tabular}

\section{KESIMPULAN}

1.Antihipertensi yang :diresepkan sebagian besar dalam bentuk tunggal $(35,47 \%)$ dan antihipertensi yang banyak diresepkan adalah amlodipine (46,37\%).

2. Terdapat $65,92 \%$ lembar resep yang memiliki potensi interaksi obat, $51,27 \%$ lembar resep yang memiliki potensi interaksi obat, dan potensi interaksi obat paling banyak berada pada level signifikasi $4(45,78 \%)$.
3.Terdapat hubungan antara banyaknya zat aktif obat dengan jumlah potensi interaksi obat yang dapat dinotasikan dengan persamaan $\mathrm{y}=$ $0,386 x-0,385$ namun hubungan tersebut lemah.

4. Terdapat hubungan antara banyaknya penyakit penyerta dengan potensi, interaksi obat yang dapat dinotasikan dengan persamaan $\mathrm{y}=$ $0,416 x+0,806$ namun hubungan tersebut sangat lemah.

\section{DAFTAR PUSTAKA}

Anonim,2010,Jumlah penduduk menurut kelompok umur, jenis kelamin, provinsi dan kabupaten/ kota 2005, http:/www.datastatistikindnesia.com/component/ option,com_tabel/task,/ltemid,165/ ,(15 juni,2010)

Anonim,2011, Interaction Checker, www. mims.com, (diakses April 2011)

Ariawan, D.S., 2010, Analisis Peresepan Antihipertensi di Wilayah Kabupaten Sleman Berdasarkan Data Resep di Apotek Pada Tahun 2008, Skripsi, Jurusan Farmasi Fakultas Matematika dan IImu Pengetahuan Alam Universitas Islam Indonesia Yogyakarta.

Bjrkman, I.K., Fastborn, J., Schmidt, I. K., Bernsten, C.B., dan . Group, T. P.C.T.E. i.E.R.P. 2002. Drug-Drug Interaction in the Elderly, The Annals of Pharmacoterapy. 1675-1681. 
Dubova, S. V. D., Hortensia ReyesMorales, Torres-Areola, L. d. P., dan Suarez-Ortega, M. 2007. Potential drug-drug and drug-disease interactions in prescriptions for ambulatory patients over 50 years of age in family medicine clinics in Mexico City, BMC Health Services Research.7. 1-8.

Lindblad, C. I., Guay, D. R. P., Hajjar, E. R., McCarthy, T. C., dan Hanlon, J. T. 2005 Geriatric, In Pharmacotherapy a phatophysiologic Approch (DiPiro, J. T., Talbert, R. L., Yee, G. C., Matzke, G. R., Wells, B. G., dan Posey, L. M., Eds.), pp 103-111, Mc.Graw-Hills, New York.

Midlov, P., Tommy, E., dan Kragh, A. 2009 Drug Related Problems in the elderly, Spinger, New York.

Saseen, J. J., dan Carter, B. L. 2005

Hypertension, In PharmcotherapyA Phatophysiologik Approch (DiPiro, J. T., Talbert, R. L., Yee, G. C., Matzke, G. R., Wells, B: G., dan Psey, L. M., Eds.), pp 185-214, Mc.Graw-Hills, New York.
Soejono, C. H., Trisna, Y., dan Puspita, T. 2004 Pedoman Pelayanan Farmasi (tata laksana terapi obat) untuk pa sien Geratri, DEPKES Rl, Jakarta.I Stockley, H. I. 2005 Drug interaction 7 th edition Pharmaceutical Press, London.

Tatro, D. S. 2001 Drug Interaction Facts, A Walters Kluwe Company, Missoury

Tumbelaka, A., Riano, P., Wirjodiarjo, M., Pudjiastuti, P., dan Firman, K. 1995 Pemiliah Uji Hipotesis, In Dasar-dasar Metodologi Penelitian Klinis (Sastroasmoro, S., dan Ismael, S., Eds.), pp 173-186, Binarupa Aksara, Jakarta.

Wolf-Maier, K., Copper, R. S., Banegas, J. R., Giampaoli, S., Hense, H.-W., Joffres, M., Primatesta, P., Rodri'guez-Artalejo, F., Stegmayr, B., Thamm, M., Tuomilehto, J., Vanuzzo, D., dan Vescio, F. 2003. Hypertension Prevalence and Blood Pressure Levels in 6 European Countries, Canada, and the United States, JAMA. 289. 2363-2369. 